\title{
Effect of emulsifiers on viscosity and emulsion stability of the cocoa powder mixture
}

\author{
${ }^{1,{ }^{*}}$ Thuy, N.M., ${ }^{2,3}$ Ha, H.T.N. and ${ }^{1}$ Tai, N.V. \\ ${ }^{1}$ Department of Food Technology, College of Agriculture, Can Tho University, Vietnam \\ ${ }^{2}$ Faculty of Agriculture and Natural Resources, An Giang University, Vietnam \\ ${ }^{3}$ Vietnam National University Ho Chi Minh City, Vietnam
}

\section{Article history:}

Received: 23 July 2020

Received in revised form: 25

August 2020

Accepted: 14 October 2020

Available Online: 1

November 2020

\section{Keywords:}

Cocoa butter,

Emulsifier,

Viscosity,

Emulsion stability,

Optimal value

\section{DOI:}

https://doi.org/10.26656/fr.2017.4(6).377

\begin{abstract}
The study was initiated to generate data on the effectiveness of emulsifiers in the cocoa mixture (use as a beverage) with the suitable cocoa butter content remaining in cocoa powder. The experimental designs and comparative analyses will provide the information and knowledge needed in using emulsifiers for improving cocoa powder dispersibility, through viscosity and emulsion stability analysis. The present study was conducted to improved cocoa powder mixtures which have good dispersibility in liquids. Emulsifier of four types (polysorbate, sorbitan monostearate, lecithin from egg yolk/vegetable oil) with the concentrations ranging from 0.25 to $0.7 \%$ on the viscosity and emulsion stability of cocoa powder (16 and $20 \%$ of cocoa butter contents remained in cocoa powder) were investigated. The obtained results showed that stabilizer levels markedly affected the viscosity and emulsion stability of whipped mixture which increased with higher levels of emulsifiers and cocoa butter contents. The dispersibility of cocoa powder can be significantly increased by adding emulsifiers with the best results achieved at 0.572 and $0.668 \%$ of sorbitan monostearate and polysorbate, respectively, in comparison with lecithin. The organoleptic evaluation on the cocoa powder samples also showed there were significant differences $(\mathrm{P} \leq 0.05)$ in the sensory attributes of the product at this concentration. This sample was adjudged the best based on the overall acceptance.
\end{abstract}

\section{Introduction}

Cocoa powder is produced from the roasted cocoa bean particles after cocoa butter is extracted. However, the cocoa butter remains in the cocoa particle as the pressing does not remove all the cocoa butter. These normally do not mix and will separate if left without an emulsifier. Addition of certain compounds as emulsifiers greatly improved the stability of emulsions of cocoa butter remained in the cocoa product when using it as a drink (Norton et al., 2019). Emulsifiers can help to make a food appealing and have a big effect on the structure and texture of many foods (Wells, 2019). A food emulsifier is a surface-active agent that acts as a border between two immiscible liquids such as oil and water, allowing them to be blended into stable emulsions (Khan et al., 2006). Emulsifiers also reduce stickiness, control crystallization and prevent separation (Hasenhuettl and Hartel, 2008). A wide range of surfactants is available, among the most commonly used emulsifiers. The most popular consumed emulsifier is the phospholipid lecithin, a natural surfactant present in all plant (typically commercially sourced from soybeans) (Kinyanjui et al., 2003), but perhaps best known as a key component of egg yolks, accounting for their emulsifier properties used to make foodstuffs such as mayonnaise. Lecithin is also used extensively in the cocoa processing industry. In instant drink powder mixes, the wetting and suspension properties of lecithin are of great importance. Sorbitan monostearate (Spans) is primarily used in the manufacture of food products as an emulsifier to keep water and oils mixed and has been approved by the European Union for use as a food additive (emulsifier) (Food Standards Agency, 2020). Within the food industry, polysorbates were used extensively in the baking industry as preservatives to enhance firmness and volume of bakery goods (Hasenhuettl and Hartel, 2008). Polysorbates 80 (Tween 80 ) also frequently incorporated usually at doses of $0.2-0.5 \%$ of flour weight into dietary products (Csáki, 2011) and often used in food to solubilize oils into water-based products, assisted the formation of stable oil-in-water emulsions and to retard 
fat bloom in chocolate products (preventing cocoa butter separation) (Partridge et al., 2019). Effect of emulsifiers on nonfat ice cream was conducted by Baer et al. (1999), the addition of either emulsifier to nonfat ice cream reduced the mean ice crystal size when compared with the control. Despite its wide application in food processing, few studies have been conducted on these emulsifiers concerning physical properties in food emulsion, the information on the quality of cocoa powder as effected by this process is still needed. Therefore, this work attempts to develop a process methodology to improve the quality of the cocoa powder. The parameters which would likely affect cocoa powder quality are types and concentrations of emulsifiers and cocoa butter on physical characteristics of whipped cocoa mixtures were investigated.

\section{Materials and methods}

\subsection{Preparation of cocoa sample}

Shelled raw cocoa beans (Forastero variety), used for this study were obtained from Vietnam. Cocoa beans are sun-dried after fermentation to reduce the moisture content from about $58-60 \%$ to about $6.5-7.5 \%$ before the cocoa can be stored (Guehi et al., 2010). The dried fermented bean was packed in bags, sealed and stored at room temperature $\left(25 \pm 11^{\circ} \mathrm{C}\right)$. Before using for the experiments, the dried beans were roasted in batches of $10 \mathrm{~kg}$ in a rotary roaster (LH-R1, Shandong, China). At the roasting temperature of $120^{\circ} \mathrm{C}$ and time of $40 \mathrm{~min}$, full chocolate flavour developed.

\subsection{Emulsifiers}

Polysorbate 80 and Sorbitan monostearate was purchased from Italia and Japan, respectively. Lecithin (egg yolk and vegetable oil) are Natures Plus's products (USA).

\subsection{Effect of the cocoa butter content and emulsifiers on physical properties of the cocoa powder mixture}

\subsubsection{Sample preparation}

Cocoa powder is obtained by hydraulic pressing (HYP305HP, Japan) of finely ground cocoa liquor (degree of fineness of 200 mesh sieve size), which must have been made from winnowed cocoa beans. Hydraulic presses can accurately obtain the required fat content in the cocoa cake. Representative samples of $1 \mathrm{~kg}$ each were obtained with two levels of cocoa butter concentration (16 and 20\%) were prepared. The experiment was randomized to get the optimum variability in the observed responses due to extraneous factor. Different degree $(0.25,0.4,0.55,0.70 \%)$ of emulsifiers (polysorbate, sorbitan monostearate, lecithin from egg yolk, lecithin from vegetable oil) were applied.

\subsubsection{Sample analysis}

\subsubsection{Measurement of viscosity}

The viscosity of each emulsion was measured for 40 seconds by using Brookfield Viscometer. The emulsions were transferred into a container and allow to stand for 20 minutes in a water bath, at $20^{\circ} \mathrm{C}$, after emulsification. The force required to drive a spindle at $60 \mathrm{rpm}$ while descending through the whipped product at a constant rate was measured just after whipping in a controlled room temperature maintained at $20 \pm 1^{\circ} \mathrm{C}$. Triplicate reading was made.

\subsubsection{Emulsion stability (ES)}

ES is the ability of the emulsion to remain stable and unchanged against coalescence. ES was measured by using a model system to test the ability of an emulsion against centrifugal force. ES was determined by using the method of Hutton and Camphbell (1977). Four levels $(0.25,0.40,0.55$ and $0.70 \%)$ of each emulsifier (as mentioned above) and two levels of cocoa butter concentration (16 and 20\%) were prepared. $10 \mathrm{~g}$ of cocoa powder with 16 and $20 \%$ of cocoa butter were added different degree of emulsifiers and mixed the mixture in Vitamix 5200 Blender (USA) and emulsified at 20,000 rpm for 2 minutes. Subsequently, the oil-water emulsion was transferred to centrifuged tubes. After incubation at room temperature for $30 \mathrm{mins}$, the emulsion tubes were centrifuged at 3,000 rpm for 30 mins. The amount of separated water was measured, and emulsion stability was calculated according to Equation 1.

$\mathrm{ES}(\%)=\frac{\mathrm{mL} \text { of water in formulation }-\mathrm{mL} \text { of water separated }}{\mathrm{mL} \text { of water in formulation }} \times 100$

\subsubsection{Sensory evaluation}

For the preparation of cocoa mixture for sensory evaluation, the amount of $10 \mathrm{~g}$ cocoa powder was used and added the optimal values of polysorbate and sorbitan monostearate (was chosen from the previous testing). The emulsifiers were melted in a hot water bath (71$\left.80^{\circ} \mathrm{C}\right)$ and added to the warm $\left(55^{\circ} \mathrm{C}\right)$ mixtures. The mixtures were whipped with Vitamix 5200 Blender Professional-Grade (USA) for 2 mins at full speed at room temperature $\left(25 \pm 1^{\circ} \mathrm{C}\right)$. Sensory evaluation of the samples was carried out by 25 panelists of judges, on a 9 -point hedonic scale for different parameters such as color, aroma, taste, texture and overall acceptability as described by Iwe (2010).

\subsection{Statistical analysis}

Statistical analysis was conducted for all of the above determinations using a statistical program 
(ANOVA), such as the multiple range tests and multiple regression analysis. Viscosity and ES were analysed by using the multiple regression analysis. A statistical analysis (STATGRAPHIC) was used to fit the model to the observed data. The proposed model (Equation 2) for each response $(\mathrm{Y})$ was:

$Y=b_{o}+\sum_{n=1}^{3} b_{n} X_{n}+\sum_{n=1}^{3} b_{n n} X_{n}^{2}+\sum_{n \neq m=1}^{3} b_{n m} X_{n} X_{m}$

Where: $b_{o}$ is $Y$-intercept (constant), $b_{n}$ is regression coefficient for the linear effect of $X_{n}$ on $Y, b_{n n}$ and $b_{n m}$ are regression coefficients for quadratic effect on $Y, X_{n}$ and $X_{\mathrm{m}}$ are independent values.

To select the acceptable condition, the multiple regression analysis was used for the data from each reference type of emulsifiers and cocoa butter content (different levels). In the multiple regression analysis, the physical characteristics (viscosity, emulsion stability) were defined as the dependent variable and the cocoa butter content, level of emulsifiers which were presented in $\mathrm{X}_{1}$, and $\mathrm{X}_{2}$ values were defined as independent variables. The reference equation was selected to fit the data, based on the $\mathrm{R}^{2}$ value obtained from the multiple regression. The selected reference equation should have a higher $\mathrm{R}^{2}$ value.

\section{Results and discussion}

\subsection{Effect of emulsifiers on the viscosity of the whipped mixture}

The effects of emulsifiers on the viscosity of the whipped mixture prepared with cocoa powder $(16 \%$ and $20 \%$ of cocoa butter) were obtained. The viscosity of cocoa mixture with a cocoa butter content of $16 \%$ was lower than the sample with higher cocoa butter content $(20 \%)$ (data not fully presented here). With all the emulsifiers and the concentrations used, the viscosity of the whipped mixture reached the higher values when the cocoa butter content in the sample was higher. The average data of viscosity of whipped mixture treated with four types of emulsifiers are presented in Table 1.

Table 1. Multiple range analysis for the viscosity (cP) of whipped mixture product with several concentrations of emulsifiers

\begin{tabular}{|c|c|c|c|c|}
\hline $\begin{array}{c}\text { Emulsifiers } \\
\text { concentration (\%) }\end{array}$ & $\begin{array}{l}\overrightarrow{0} \\
\stackrel{0}{<} \\
0 \\
0 \\
\vec{c} \\
\frac{\overrightarrow{0}}{0}\end{array}$ & 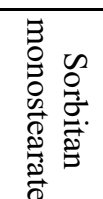 & 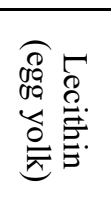 & 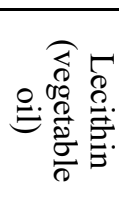 \\
\hline 0.00 & $2.325^{\mathrm{a}}$ & $2.325^{\mathrm{a}}$ & $2.338^{\mathrm{a}}$ & $2.325^{\mathrm{a}}$ \\
\hline 0.25 & $3.250^{\mathrm{b}}$ & $3.637^{\mathrm{b}}$ & $2.875^{\mathrm{b}}$ & $3.063^{\mathrm{b}}$ \\
\hline 0.40 & $3.425^{b}$ & $3.837^{\mathrm{b}}$ & $2.963^{b}$ & $3.163^{b c}$ \\
\hline 0.55 & $3.950^{\mathrm{c}}$ & $4.112^{\mathrm{c}}$ & $3.275^{\mathrm{c}}$ & $3.213^{\mathrm{cd}}$ \\
\hline 0.70 & $4.075^{\mathrm{c}}$ & $4.338^{\mathrm{c}}$ & $3.400^{\mathrm{c}}$ & $3.263^{\mathrm{d}}$ \\
\hline
\end{tabular}

Data are expressed as the mean of triplicate testing. Means with the same superscript within column are not significantly different at 5\% according to Multiple Range Test
By changing the concentrations of emulsifiers, the viscosity was affected. The viscosity of emulsions prepared by a concentration of 0.25 and $0.4 \%$ was relatively low. The highest viscosity was observed in emulsions prepared at a concentration of 0.55 to $0.7 \%$ for each type of emulsifier used. There were not change between emulsions prepared with lecithin (egg yolk) and lecithin (vegetable oil). The highest viscosity obtained by using polysorbate and sorbitan monostearate treatment. It showed that the rise of viscosity before phase conversion, increased viscosity is a characteristic of natural buttercream. This implied that long agitation time was accompanied by the incorporation of numerous small air bubbles. Syed et al. (2018) indicated that emulsifiers added mixes had more viscosity due to stickiness of fat particles and the viscosity increase was attributed to the solidification of fat due to aggregation during the process of ageing. In the study of Mulder and Walstra (1974), they found that the air bubbles practically formed a foam layer on top of the cream. Inclusion of air may have a major effect on coalescence as it causes an irreversible reduction of interfacial area. The quadratic models for the viscosity of the whipped mixture of polysorbate, sorbitan monostearate, lecithin (egg yolk) and lecithin (vegetable oil) are presented on Equation 3, 4, 5 and 6. In these cases, almost effects have P-values less than 0.05 , indicating that they are significantly at $95.0 \%$ confidence level.

$\mathrm{V}_{1}=1.171+0.0659 \mathrm{X}_{1}-2.132 \mathrm{X}_{2}+0.296 \mathrm{X}_{1} \mathrm{X}_{2}-$ $0.938 \mathrm{X}_{2}^{2}$

$\mathrm{R}^{2}=94.633 \%, \mathrm{R}^{2}$ (adjusted for d.f.) $=90.34 \%$,

$\mathrm{SEE}=0.246$

$\mathrm{V}_{2}=1.924+0.025 \mathrm{X}_{1}+3.403 \mathrm{X}_{2}+0.114 \mathrm{X}_{1} \mathrm{X}_{2}-$ $3.887 \mathrm{X}_{2}^{2}$

$\mathrm{R}^{2}=97.692 \%, \mathrm{R}^{2}$ (adjusted for d.f.) $=95.845 \%$, $\mathrm{SEE}=0.155$

$V_{3}=2.048+0.017 X_{1}-1.508 X_{2}+0.195 X_{1} X_{2}-$ $0.714 X_{2}^{2}$

$\mathrm{R}^{2}=97.925 \%, \mathrm{R}^{2}$ (adjusted for d.f.) $=96.265 \%$, $\mathrm{SEE}=0.086$

$\mathrm{V}_{4}=0.717+0.091 \mathrm{X}_{1}-2.027 \mathrm{X}_{2}+0.294 \mathrm{X}_{1} \mathrm{X}_{2}$ $2.881 \mathrm{X}_{2}^{2}$

$\mathrm{R}^{2}=96.689 \%, \mathrm{R}^{2}$ (adjusted for d.f.) $=94.041 \%$, $\mathrm{SEE}=0.144$

Where $\mathrm{V}_{1}, \mathrm{~V}_{2}, \mathrm{~V}_{3}, \mathrm{~V}_{4}$ are the viscosity of whipped mixture for polysorbate, sorbitan monostearate, lecithin (egg yolk) and lecithin (vegetable oil) used, respectively. $\mathrm{X}_{1}$ is cocoa butter content in cocoa powder, as independent value and $X_{2}$, is the concentration of emulsifiers used in treatment, as independent value. 
The response surfaces results for viscosity are shown in Figure 1, 2, 3 and 4. The higher $\mathrm{R}^{2}$ values of these models indicated a good fit of the data.

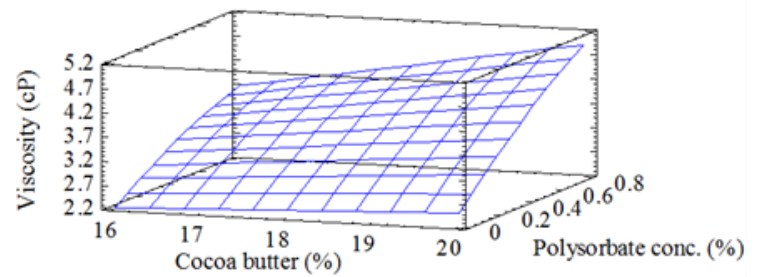

Figure 1. Influence of cocoa butter content and polysorbate concentrations on the viscosity of the whipped mixture.

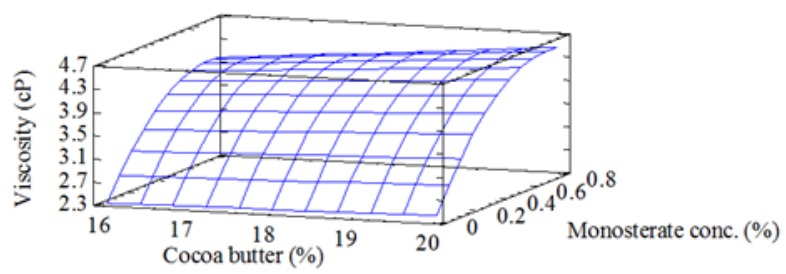

Figure 2. Influence of cocoa butter content and sorbitan monostearate concentrations on the viscosity of the whipped mixture.

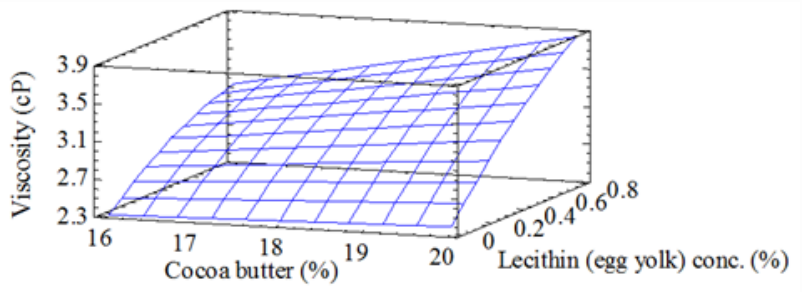

Figure 3. Influence of cocoa butter content and lecithin (egg yolk) concentrations on the viscosity of the whipped mixture.

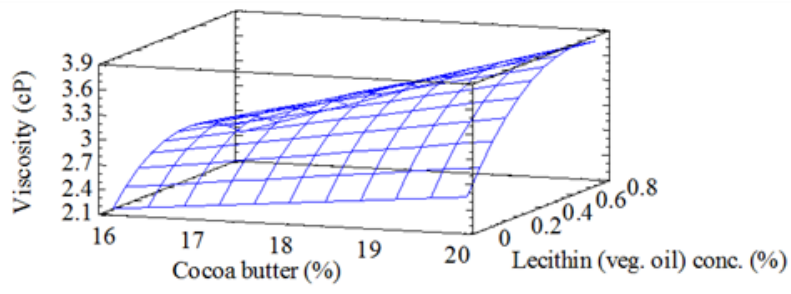

Figure 4. Influence of cocoa butter content and lecithin (vegetable oil) concentrations on the viscosity of the whipped mixture.

These models are useful as an indicator on which variables to be changed to maximize the viscosity. This implied that viscosity of whipped mixture could be estimated by cocoa butter content and emulsifier concentrations.

\subsection{Effect of emulsifiers on the emulsion stability (ES) of the whipped mixture}

Factors affecting the stability of emulsion were investigated, including cocoa butter content, emulsifying agent and emulsifier concentrations. Emulsions of all cocoa butter samples showed increased ES as cocoa butter content increased (16 to 20\%) (data not shown). Increasing cocoa butter content and emulsifier concentrations facilitates adsorption of more butter, which increases the stability of the emulsions. The greatest stability of cocoa powder at a higher concentration of emulsifiers and higher cocoa butter content (20\%) and also reflect increased viscosity of the dispersion. These characteristics caused the butter to rapidly adsorb at the oil-water interface and to produce a stabilizing film surrounding the oil droplets, protecting them against flocculation, coalescence and oiling off (Matsumiya et al., 2009; Murry et al., 2011; Fischer and Windhab, 2011). The interfacial properties depended on butter content, emulsifier concentrations and different type of emulsifiers in comparative studies.

The highest ES obtained by using polysorbate and sorbitan monostearate treatment. The corresponding maximum ES of cocoa powder with polysorbate and sorbitan monostearate treatments were higher in comparison with lecithin (egg yolk and vegetable oil) (Table 2). O'Brien (2003) showed that sorbitan monostearate, the most common of the surfactants that require dispersion in water and fat use. This emulsifier can be used for icing, whipped topping and stability characteristics. Polysorbate 60 can be used in application similar sorbitan ester in cakes, whipped toppings. Polysorbate 80 can be used in a wide range of application as a solubilizing and dispersing agent in some food application. The quadratic models for ES of several types of emulsifiers are represented in the following equations (Equation 7, 8, 9 and 10). In these cases, almost effects have P-values less than 0.05 , indicating that they are significantly different at $95.0 \%$ confidence level. $\mathrm{ES}_{1}=0.870+0.138 \mathrm{X}_{1}+9.636 \mathrm{X}_{2}+0.293 \mathrm{X}_{1} \mathrm{X}_{2}-$
$11.594 \mathrm{X}_{2}^{2}$

$\mathrm{R}^{2}=96.383 \%, \mathrm{R}^{2}$ (adjusted for d.f.) $=93.49 \%$, $\mathrm{SSE}=0.506$

$\mathrm{ES}_{2}=2.841+0.027 \mathrm{X}_{1}+16.844 \mathrm{X}_{2}+0.163 \mathrm{X}_{1} \mathrm{X}_{2}$ $17.565 \mathrm{X}_{2}^{2}$

$\mathrm{R}^{2}=96.426 \%, \mathrm{R}^{2}$ (adjusted for d.f.) $=93.567 \%$, $\mathrm{SEE}=0.563$

$\mathrm{ES}_{3}=2.233+0.06 \mathrm{X}_{1}+12.745 \mathrm{X}_{2}+0.0196 \mathrm{X}_{1} \mathrm{X}_{2}-$ $11.353 \mathrm{X}_{2}^{2}$

$\mathrm{R}^{2}=97.044 \%, \mathrm{R}^{2}$ (adjusted for d.f.) $=94.679 \%$, $\mathrm{SEE}=0.347$

$\mathrm{ES}_{4}=2.534+0.048 \mathrm{X}_{1}+9.106 \mathrm{X}_{2}-0.302 \mathrm{X}_{1} \mathrm{X}_{2}+$ $0.696 \mathrm{X}_{2}^{2}$

$\mathrm{R}^{2}=90.432 \%, \mathrm{R}^{2}$ (adjusted for d.f.) $=82.778 \%$, $\mathrm{SEE}=0.471$

Where $\mathrm{ES}_{1}, \mathrm{ES}_{2}, \mathrm{ES}_{3}, \mathrm{ES}_{4}$ are emulsion stability of whipped mixture for polysorbate, sorbitan monostearate, lecithin (egg yolk) and lecithin (vegetable oil) used, respectively. $\mathrm{X}_{1}$ is cocoa butter content (\%) and $\mathrm{X}_{2}$ is the 
concentration of emulsifiers (\%).

These relationships have high $\mathrm{R}$-squared values indicating a good fit of the data. The response surface variables are presented in Figure 5, 6, 7 and 8. This implied that ES could be estimated by cocoa butter content and emulsifier concentrations.

Table 2. Emulsion stability (\%) of whipping mixture for several types and level of emulsifiers

\begin{tabular}{|c|c|c|c|c|}
\hline $\begin{array}{c}\text { Emulsifiers } \\
\text { concentration (\%) }\end{array}$ & $\begin{array}{l}\overrightarrow{0} \\
\stackrel{0}{<} \\
0 \\
0 \\
\overrightarrow{0} \\
\overrightarrow{0}\end{array}$ & 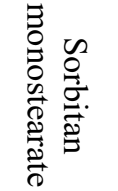 & 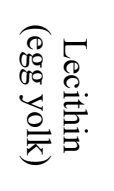 & 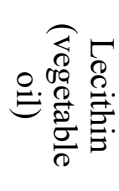 \\
\hline 0.00 & $3.352^{\mathrm{a}}$ & $3.165^{\mathrm{a}}$ & $3.218^{\mathrm{a}}$ & $3.268^{\mathrm{a}}$ \\
\hline 0.25 & $6.380^{\mathrm{b}}$ & $7.777^{b}$ & $6.079^{\mathrm{b}}$ & $4.747^{\mathrm{b}}$ \\
\hline 0.40 & $7.440^{c}$ & $8.052^{b}$ & $6.643^{c}$ & $4.887^{\mathrm{b}}$ \\
\hline 0.55 & $8.058^{\mathrm{d}}$ & $8.630^{c}$ & $6.795^{\mathrm{c}}$ & $5.215^{\mathrm{b}}$ \\
\hline 0.70 & $8.118^{\mathrm{d}}$ & $8.713^{c}$ & $7.088^{\mathrm{d}}$ & $6.527^{\mathrm{c}}$ \\
\hline
\end{tabular}

Data are expressed as the mean of triplicate testing. Means with the same superscript within column are not significantly different at 5\% according to Multiple Range Test

3.3 Comparison the average data of viscosity and emulsion stability of whipped mixture for four types of emulsifiers used

The selection of four types of a stabilizer such as a polysorbate, sorbitan monostearate, lecithin (egg yolk) and lecithin (vegetable oil) for this experiment did not imply that certain other commercial blends of stabilizers may not have been equally satisfactory (data not shown).

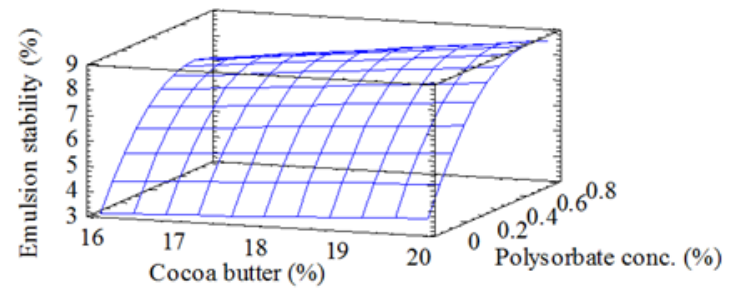

Figure 5. Influence of cocoa butter content and polysorbate concentrations on emulsion stability of the whipped mixture.

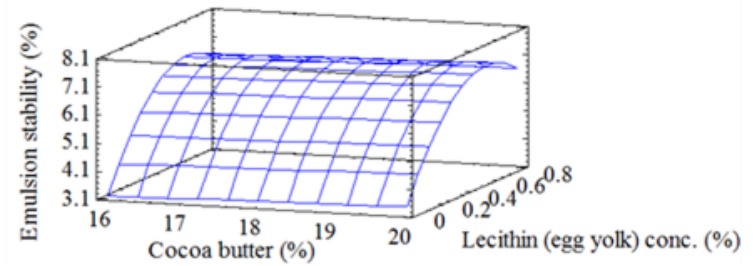

Figure 7. Influence of cocoa butter content and lecithin (egg yolk) concentrations on emulsion stability of the whipped mixture.
The analysis of variance was used to compare the average data of viscosity and emulsion stability of whipped mixture and the results are given in Table 3.

Table 3. Analysis of viscosity and emulsion stability of whipped mixture for several types of emulsifiers

\begin{tabular}{lcc}
\hline \multicolumn{1}{c}{ Emulsifiers type } & Viscosity (cP) & $\begin{array}{c}\text { Emulsion stability } \\
(\%)\end{array}$ \\
\hline Polysorbate & $3.65^{\mathrm{a}}$ & $6.67^{\mathrm{b}}$ \\
Sorbitan monostearate & $3.65^{\mathrm{a}}$ & $7.28^{\mathrm{a}}$ \\
Lecithin (egg yolk) & $3.00^{\mathrm{b}}$ & $4.93^{\mathrm{d}}$ \\
Lecithin (oil vegetable) & $2.97^{\mathrm{b}}$ & $5.97^{\mathrm{c}}$ \\
\hline
\end{tabular}

Data are expressed as the mean of triplicate testing. Means with the same superscript within column are not significantly different at $5 \%$ according to Multiple Range Test

To determine the optimum level of emulsifiers used, whipped mixtures were prepared, and the levels varied from $0.25-0.7 \%$ with an increment of $0.15 \%$. Stabilizer levels markedly affected the viscosity and emulsion stability of the whipped mixture. The concentration of $0.55 \%$ of each emulsifier resulted in highly significant changes when using it for the whipped products. Polysorbate and sorbitan monostearate has been shown to increase the dispersibility and emulsion stability compared to two types of lecithin at the same concentration used. In most cases, the results of ANOVA showed that the emulsifier concentrations significantly affected the physical properties of the cocoa powder mixture, e.g. in the cases of polysorbate and sorbitan monostearate used, the emulsion stability of each

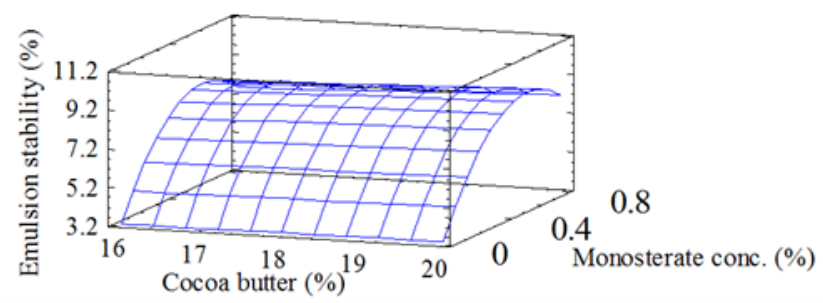

Figure 6. Influence of cocoa butter content and sorbitan monostearate concentrations on emulsion stability of the whipped mixture.

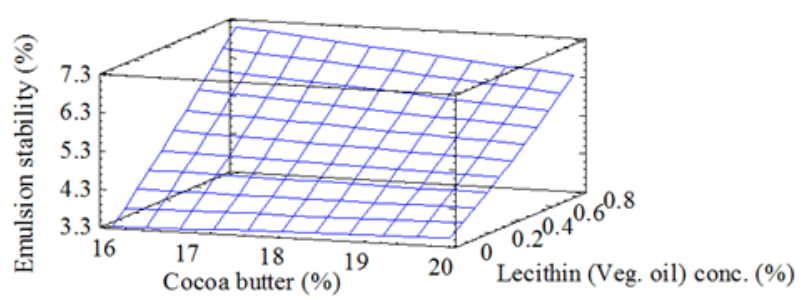

Figure 8. Influence of cocoa butter content and lecithin (vegetable oil) concentrations on emulsion stability of the whipped mixture.

Table 4. Optimize Response emulsion stability of mixture with sorbitan monostearate and polysorbate used

\begin{tabular}{lcccccc}
\hline \multirow{2}{*}{ Factors } & \multicolumn{3}{c}{ Sorbitan monostearate } & \multicolumn{3}{c}{ Polysorbate } \\
\cline { 2 - 7 } & Low & High & Optimum & Low & High & Optimum \\
\hline Concentration of emulsifier (\%) & 0.0 & 0.7 & 0.572 & 0.0 & 0.7 & 0.668 \\
Optimum value of emulsion stability (\%) & & 9.133 & & & 8.813 & \\
\hline
\end{tabular}



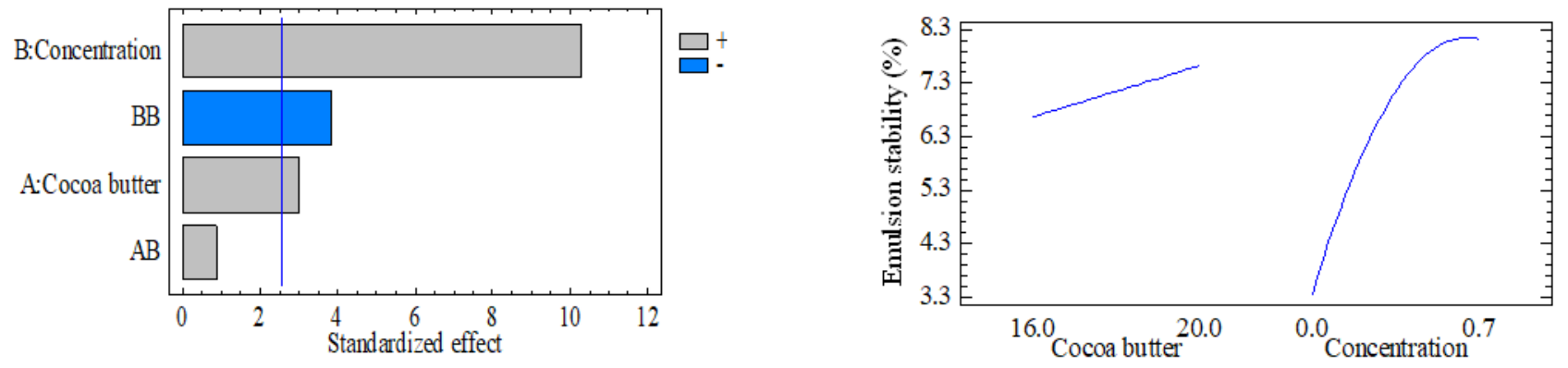

Figure 9. Standardized Pareto chart (left side) and main effect plot (right side) for emulsion stability of polysorbate used.
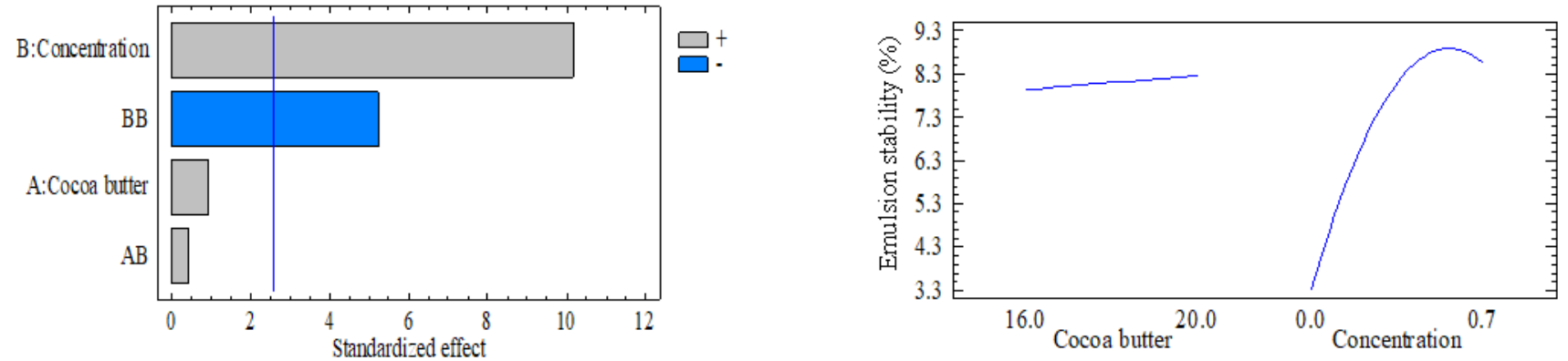

Figure 10. Standardized Pareto chart (left side) and main effect plot (right side) for emulsion stability of sorbitan monostearate used.

emulsion is shown in Figure 9 and 10 with plots the estimates in decreasing order of importance. The results in Table 4 showed the combination of factor levels which maximizes emulsion stability of whipped mixtures in the cases of sorbitan monostearate and polysorbate over the indicated region.

\subsection{Sensory evaluation}

The average overall acceptability scores for all the cocoa powder samples (Table 5) revealed that $20 \%$ cocoa butter remaining in cocoa powder is the best acceptable score.

In addition, cocoa powders which were prepared with $0.57 \%$ sorbitan monostearate had higher scores of overall acceptability (8.61) which was found to be significantly higher at $\mathrm{P}<0.05$ in comparison to polysorbate treatment.

Table 5. Summary of sensory analysis for cocoa powder

\begin{tabular}{|c|c|c|c|c|c|}
\hline Treatments & $\begin{array}{l}\overrightarrow{0} \\
\overrightarrow{0} \\
\overrightarrow{0}\end{array}$ & $\frac{\rho}{\rho}$ & $\begin{array}{l}\vec{Q} \\
\stackrel{\ddot{x}}{\Xi} \\
\overrightarrow{0}\end{array}$ & 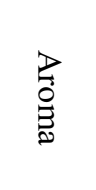 & 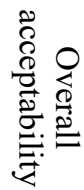 \\
\hline Polysorbate $0.67 \%$ & $7.82^{\mathrm{a}}$ & $7.74^{\mathrm{a}}$ & $8.38^{b}$ & $8.74^{\mathrm{a}}$ & $8.14^{\mathrm{b}}$ \\
\hline $\begin{array}{l}\text { Sorbitane } \\
\text { monosterate } 0.57 \%\end{array}$ & $7.83^{\mathrm{a}}$ & $7.75^{\mathrm{a}}$ & $9.23^{\mathrm{a}}$ & $8.79^{\mathrm{a}}$ & $8.61^{\mathrm{a}}$ \\
\hline
\end{tabular}

Values with different superscripts within column are significantly different $(\mathrm{p}<0.05)$.

\section{Conclusion}

This study demonstrated the effect of butter content and emulsifier combination on stability in the emulsion.
Comparative studies of physical properties of cocoa powder mixture as affected by cocoa butter content and concentration of emulsifiers, it was observed that the concentration of each emulsifier was effective stabilizer of fat-water emulsion. The optimum value of each emulsifier was determined by ANOVA testing. Sorbitan monostearate and polysorbate prove more effective than lecithin in stabilizing emulsions with the optimum concentration used of 0.572 and $0.668 \%$, respectively. The sensory acceptability of the cocoa powder produced had improved significantly the sensory acceptability of the cocoa powder. The present study demonstrated a universal nature of emulsifiers to stabilise oil-in-water emulsions and provided a basic understanding for polysorbate, sorbitan monostearate and lecithin used in improving the properties and stability of the complex emulsion. The future works could focus on the structure, function, and application of sorbitan monostearate and polysorbate stabilized emulsions in different food products.

\section{Conflict of interest}

The authors declare no conflict of interest.

\section{References}

Baer, R.J., Krishnaswamy, N. and Kasperson, K.M. (1999). Effect of Emulsifiers and Food Gum on Nonfat Ice Cream. Journal of Dairy Science, 82(7), 1416-1424.

https://doi.org/10.3168/jds.S0022-0302(99)75368-3

Csáki, K.F. (2011). Synthetic surfactant food additives can cause intestinal barrier dysfunction. Medical 
Hypotheses, 76(5), 676-81. https://doi.org/10.1016/ j.mehy.2011.01.030

Fischer, P. and Windhab, E.J. (2011). Rheology of food materials. Current Opinion in Colloid and Interface Science, 16(1), 36-40. https://doi.org/10.1016/ j.cocis.2010.07.003

Food Standards Agency. (2020). Approved additives and E numbers. Retrieved from Food Standards Agency website: https://www.food.gov.uk/businessguidance/approved-additives-and-e-numbers

Guehi, T.S., Zahouli, I.B., Ban-Koffi, L., Fae, M.A. and Nemlin, J.G. (2010). Performance of different drying methods and their effects on the chemical quality attributes of raw cocoa material. International Journal of Food Science and Technology, 45(8), 1564-1571. https://doi.org/10.1111/j.13652621.2010.02302.x

Hasenhuettl, G.L. and Hartel, R.W. (Eds.) (2008). Food emulsifiers and their applications. 2nd ed., p. $1-$ 426. New York, USA: Springer. https:// doi.org/10.1007/978-0-387-75284-6_1

Hutton, C.W. and Campbell, A.M. (1977). Functional properties on a soy concentrate and a soy isolate in simple systems and in a food system. Journal of Food Science, 42(2), 457-460. https:// doi.org/10.1111/j.1365-2621.1977.tb01522.x

Iwe, M.O. (2010). Handbook of Sensory Methods and Analysis, p. 75-78. Uwani-Enugu, Nigeria: Rojoint Communication Services Ltd.

Khan, A.Y., Talegaonkar, S., Iqbal, Z., Ahmed, F.J. and Khar, R. K. (2006). Multiple emulsions: an overview. Current Drug Delivery, 3(4), 429-43.

Kinyanjui, T., Artz, W. and Mahungu, S. (2003). Emulsifiers: Organic Emulsifiers. In Caballero, B., Trugo, L. and Finglas, P.M. (Eds). Encyclopedia of Food Sciences and Nutrition, p. 2070-77. Amsterdam: Elsevier Science Ltd. https:// doi.org/10.1016/B0-12-227055-X/00401-6

Matsumiya, K., Takahashi, W., Inoue, T. and Matsumura, Y. (2010). Effects of bacteriostatic emulsifiers on the stability of milk-based emulsions. Journal of Food Engineering, 96(2), 185-191. https://doi.org/10.1016/j.jfoodeng.2009.07.012

Mulder, H. and Walstra, P. (1974). The milk fat globule: emulsion science as applied to milk products and comparable foods, p. 213-215. Wageningen, the Netherlands: PUDOC.

Murry, B.S., Durga, K., Yusoff, A. and Stoyanov, S. (2011). Stabilization of foams and emulsions by mixtures of surface-active food-grade particles and proteins. Food Hydrocolloids, 25(4), 627-638. https://doi.org/10.1016/j.foodhyd.2010.07.025
Norton, J.E., Fryer, P J., Parkinson, J.A. and Cox, P. (2019). Development and characterisation of tempered cocoa butter emulsions containing up to 60\% water. Journal of Food Engineering, 95(1), 172 -178. https://doi.org/10.1016/j.jfoodeng.2009.04.026

O'Brien, R.D. (2003). Fats and Oils: Formulating and processing for application. 2nd ed. USA: CRC Press. https://doi.org/10.1201/9780203483664

Partridge, D., Lloyd, K.A., Rhodes, J.M. and Walker, A.W. (2019). Assessing the impact of exposure to permitted emulsifiers on the bowel and metabolic health - introducing the FADietsstudy. Nutrition Bulletin, 44(4), 329-349. https://doi.org/10.1111/ nbu. 12408

Syed, Q.A., Anwar, S., Shukat, R. and Zahoor, T. (2018). Effects of different ingredients on the texture of ice cream. Journal of Nutritional Health and Food Engineering, 8(6), 422-435. https:// doi.org/10.15406/jnhfe.2018.08.00305.

Wells, H. (Ed.) (2019). Food Science and Food Biotechnology. $1^{\text {st }}$ ed. United Kingdom: ED Tech Press. 